selected from the hundreds of thousands commissioned by the Farm Security Administration in the United States after the depression. ${ }^{5}$ Their commentary greatly adds to an understanding of the photographs, which look, on first sight, to be self explanatory. To check documentary photographs' "inherent tendency to fraudulence" Stoeckle and White suggest shifting the burden of meaning from the producer (the photographer) to the consumer (the audience). "Burden" is the right word: this is hard work.

Incorporating the sorts of images found in this issue into histories of medicine has hardly begun. So far all that has been agreed is that medical images are not transparent windows on the past, and defining what they are will be difficult. ${ }^{6}$ In the historical papers published in this issue the hard work of evaluating primary sources has already been done: they are an easy read. Meanwhile, the medical images obstinately remain as primary sources, pending their informed interrogation. For once, looking at the pictures is the more arduous option.

Senior Assistant Editor,

TONY DELAMOTHE $B M \mathcal{F}$

1 Schupbach W. Iconographic collections. London: Wellcome Institute for the History of Medicine, 1989.

Anonymous. Medicine through the artist's eye. London, Science Museum, 1978.

3 Porter R. Prinney, Boney, Boot. London Review of Books 1986;8(No 5):129-30.

4 Fox DM, Lawrence C. Photographing medicine: images and power in Britain and America since 1840. Westport, Connecticut: Greenwood, 1988

Stoeckle JD, White G A. Plain pictures of plain doctoring: vernacular expression in New Deal medicine

and photography. Cambridge, Massachusetts: MIT 1985.

6 Jordanova L. Medicine and visual culture. Social History of Medicine 1990;3(No 1):89-99.

\title{
The population bomb has exploded already
}

\section{Twice as many people are alive in 1990 as were in 1950}

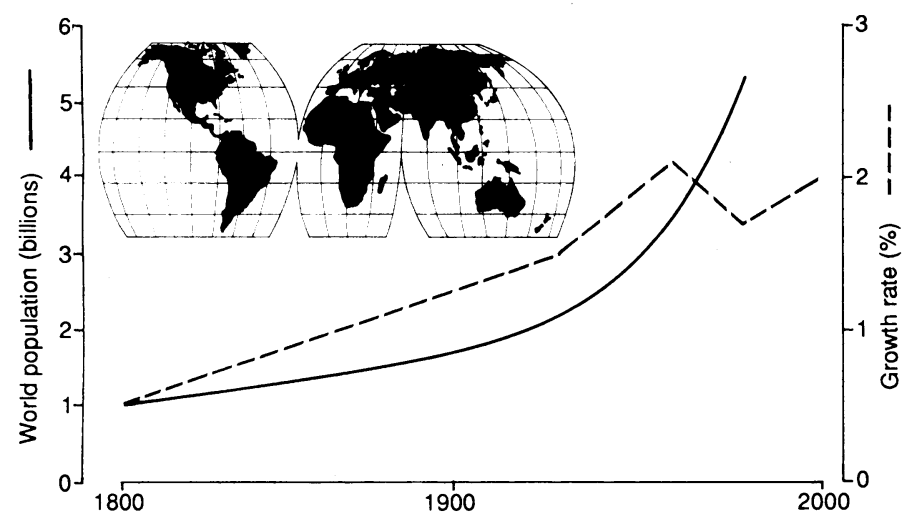

The growth of the population is exponential: despite a slowing of the growth rate the amount by which the population increases is greater year by year. Population grows like a tumour, not like a tree

In all the recent concern about threats to the environment from global warming, ozone depletion, loss of rain forests, and industrial pollution remarkably little prominence has been given to the prime cause of these problems-overpopulation.

Warnings about population growth began with Darwin's contemporary Malthus, but scientists and other concerned people began to talk seriously of an imminent population explosion in the late 1960 s, when the growth rate worldwide had reached $2 \cdot 1 \% .^{2}$ At that time the total world population was around 3.5 billion; now it is 5.4 billion and growing arithmetically faster than ever before (figure). ${ }^{3}$ Yet paradoxically people seem less worried. Part of the explanation is a decline in the growth rate to $1.7 \%$ in the mid-1980s, combined with close to zero growth rates in some European countries. ${ }^{\star}$ These data allowed those who wanted reassurance to find it: they could believe that the population explosion had been brought under control. They were wrong.

Other reasons for complacency among politicians and ecologists about population have to do with soft concepts and attitudes ranging from the instinctive biological imperative to go forth and multiply to the recognition in many developing countries that the more people a nation has the more powerful it is likely to be. There are still influential voices arguing that

^A growth rate of $1.7 \%$ means that there are 17 more births than deaths per 1000 people per year. Roughly, $2 \%$ growth gives a doubling time of 40 years. the world can support many more than its present population and that any attempts to restrain natural growth are immoral - and when calls for restraint are directed from the West to the other nations they are also often stigmatised as racist, neocolonialist, and patronising.

In reality, the population bomb has already exploded: the world has too many people and will soon have many more. The best we can hope to do in the 1990s is to minimise the damage for future generations. After 40 years in which worldwide increases in food production have outstripped growth in population the balance has recently been reversed. The numbers of mouths to feed are now growing faster than the stocks of food.

In the 1980s the amount of cropland available for growing the world's food declined by $7 \%$ - largely because it became useless desert or was otherwise exhausted. Virtually all the reasonable arable land in the world is being farmed, and agriculture cannot be expected to become much more efficient. The limiting factor is the rate at which the sun's energy can be converted into organic molecules by photosynthesis. The two essential resources for growth of crops are topsoil and groundwater. Soil takes millennia to replace, yet an estimated 25 billion tons a year is being washed or blown away all round the world. ${ }^{2}$ Water is being drawn from underground aquafers at rates that are rapidly lowering the water tables. Much of this water accumulated during the last ice age and, like topsoil, will take millennia to replace. Irrigation is, furthermore, damaging to soil in the long term - which explains the destruction by salinisation of vast areas of land in the United States and the Soviet Union.

Current food production just feeds the world's current population with around one fifth of it hungry. True, if everyone ate a simple, basic vegetarian diet there would be enough for perhaps six billion - the projected population in the middle of this decade. But current worldwide food production would provide a European or North American style diet for only 2.5 billion people, less than half the current population. As the Third World nations become more affluent there will not be enough food to satisfy their peoples. Maurice King's sober analysis in the Lancet (15 September) described the demographic trap faced by many developing countries - an unsustainable state with high birth and death rates and a rapidly deteriorating environment. ${ }^{+}$

What, then, can be done to persuade politicians, religious 
leaders, and the mass of ordinary people that the world has exceeded its biological limit? Firstly, some fallacies must be exposed and shown to be both mistaken and dangerous.

- People are told that population growth is declining everywhere so long term there is no problem. The reality is that even a final, stable world population size of 10 billion-double the present figure-will be an unrealistic target unless the current high birth rates in Africa and Asia are cut substantially in the current decade

- People are told that food production can be increased a lot further by use of new technologies. In fact the world's food supply is already inadequate, and there is no immediate prospect of any innovation that will increase the supply of cheap staples such as wheat and rice

- People are told that as countries become richer their population growth rates decline. True, but the countries such as Kenya with the highest growth rates are becoming poorer as they have to import more food and more of their workforce become unemployed

- People are told that countries such as The Netherlands and Hong Kong remain prosperous despite population densities far greater than anything in Africa. True, but these countries import most of their food and raw materials. Very few high density communities of this kind are sustainable long term. A country (or a planet) is overpopulated when it has more people than the land's carrying capacity.

What can be done? The first task - and one which doctors should recognise as a public health duty - is to make population growth as much a public concern as global warming and other ecological concerns. Most people do not understand exponential growth-it needs to be explained with easy examples such as lilies growing in ponds or bottles becoming full (and half full only one doubling time before disaster).

Secondly, doctors should speak up for the organisations promoting population policies and criticise (or at least not support) the groupings - religious, racial, or political - which oppose the provision of contraception and abortion. The Lancet's editorial accompanying King's article made the important point that poor countries cannot afford to buy the contraceptives they need; yet a penny a day from each Western taxpayer would meet the costs of global family planning needs. Family planning technologies are only part of the answer to population growth: they need to be accompanied by education campaigns and by health and economic reforms. But, in my view, when the history of the twentieth century comes to be written it will be hard to explain the thinking of the opponents of population restraint, the antiabortion campaigners, and the legislators who outlaw contraception. Sooner or later everyone will recognise the devastating consequences of overpopulation: the sooner that time comes the less devastating will be the effects on the quality of life for future generations.

Associate Editor,

TONY SMITH

$B M 7$

1 McKibben B. Reflections. The end of nature. New Yorker 1989 Sept 11:47-105.
2 Ehrlich P. The population bomb. New York: Ballantine, 1968 .
3 Ehrlich PR, Ehrlich AH. The population explosion. New York: Simon and Schuster, 1990 .
4 King M. Health is a sustainable state. Lancet 1990;ii:664-7.

5 Anonymous. Nothing is unthinkable. Lancet 1990;ii:659-61. 